\title{
Nanotechnology and modern materials as a way to make road transportation cleaner
}

\author{
P. Fuć \\ Institute of Combustion Engines and Transport, \\ Poznan University of Technology, Poland
}

\begin{abstract}
There is no doubt that the share of newly registered vehicles fitted with combustion engines will grow, particularly those fitted with diesel engines for their much lower fuel consumption. Due to the specificity of the diesel engines and the issues related to NOx and PM emission, continuous research is being done in order to reduce those emissions. Investigations continue to implement new technologies such as the addition of urea into the exhaust gases to generate a NOx reducing atmosphere or to reduce the maximum temperature of PM ignition. Another rapidly developing branch is nanotechnology and thermoelectric materials.

This article presents the possibility of the application of nanostructural materials in order to increase the environment friendliness of certain vehicle subassemblies. Methods of energy recuperation with the use of thermoelectric materials have also been presented. The authors aim to develop an aftertreatment system with low temperature energy recuperation from the exhaust gases.
\end{abstract}

Keywords: nanotechnology, aftertreatment, recuperation.

\section{DPF with nanoparticle catalysts}

A very active area of development in the DPF field is optimization of the system.

Today, there are three primary filter materials in significant series production: $\mathrm{SiC}$, cordierite, and aluminum titanate and others. Ohno et al. describe that latest material developments for it by improving the bond contact area with $\mathrm{SiC}$ grains and by adjusting filter porosity, the thermal conductivity of the material increases relative to other $\mathrm{SiC}$ materials, allowing for a higher critical soot loading limit. Finally, it is difficult to develop a successful new DPF material, as 
evidence that $\mathrm{SiC}$ and cordierite have been present in DPF applications for more than a decade and still compose more than $90 \%$ of the filter market [3].

Mazda Motor Corporation has unveiled a new generation of catalytic converters that use 70 to 90 per cent less of the precious metals, which help to purify an exhaust emissions. The catalytic converters rely on nanoparticles of the catalytic metal, each less than five nanometres across, studded onto the surface of tiny ceramic spheres. The catalyst material has been achieved that features single, nanosized precious metal particles embedded in fixed position [7].

Japanese automaker Nissan announced it had developed a nanotechnologybased catalyst that would cut its precious metals usage by 50 per cent. Nissan, which will share the technology with French partner Renault, intends to launch a new vehicle using the catalyst in late 2008 or early 2009 [4].

The first part of this work was a preliminary discernment of the possibility of application of $\mathrm{Pd}-\mathrm{Au}-\mathrm{Ag}-\mathrm{Ni}-\mathrm{Co}$ (non $\mathrm{Pt}$ ) nanometric, powder alloy as an active part of a PM- filter. The hollow part structure of $\mathrm{TiO}_{2}-\mathrm{RuO}_{2}$ (washcoat) has been proposed as the active layer on the catalyst support, composed of SiC. The washcoat has been obtained by the USPD method (Ultra Spray Pyrolysis Deposition). The influence of the preparation conditions such as: flow velocity, salt concentration, temperature and process atmosphere on the size and shape of $\mathrm{TiO}_{2}-\mathrm{RuO}_{2}$ particles has been determined.

\section{Experimental}

$\mathrm{RuO}_{2}$ is one of the most widely applied oxide catalyst materials owing to its high chemical stability, lower cost than Pt and good flexibility in fabrication. Such $\mathrm{RuO}_{2}$ nanomaterials are especially attractive due to their tunable electronic and optoelectronic properties.

The experimental setup for the synthesis of nanoparticles by flame spray pyrolysis is shown in Figure 1. The precursor solutions consisted of titanium (97\%, Aldrich) and $\mathrm{RuCl}_{2}$ dissolved in an Isopropyl-Alcohol $20 \mathrm{vol} \%$. The liquid precursor mixture is rapidly dispersed by a gas stream of oxygen and ignited by a premixed methane/ oxygen flame.

The ruthenium films were annealed in oxygen atmosphere in temperature range of $653-1073 \mathrm{~K}$ during $4-48 \mathrm{~h}$. This process leads to partially oxidation of ruthenium and formation bilayers coating of $\mathrm{RuO}_{2} / \mathrm{Ru}$. The ruthenium film obtained by PVD technique has agglomerated particles. The $\mathrm{TiO}_{2}-\mathrm{RuO}_{2}$ dispersion, the $\mathrm{TiO}_{2}-\mathrm{RuO}_{2}$ sizes and the accurate size of particle can be determined by TEM, and HRTEM measurements.

Figure 2 shows HRTEM bright field images of samples $\mathrm{TiO}_{2}-\mathrm{RuO}_{2}$ with different magnifications. The corresponding diffraction patterns are shown in the insets. Figures show the bright field images of the FSP made nanoparticles spheres, which were polyhedral aggregated of primary particles. Figures 3, 4 HREM gives the EDS elemental composition signal. Figure 5 shows the morphologies of flame made sphere $\mathrm{TiO}_{2}-\mathrm{RuO}_{2}$. Point 1 emphasized clearly yield a signal corresponding to $\mathrm{Ti}$ and $\mathrm{Ru}$. Figure 6 shows the crystal defects of flame made sphere $\mathrm{TiO}_{2}-\mathrm{RuO}_{2}$. The defects are the most severe ones affecting the structural properties of $\mathrm{TiO}_{2}-\mathrm{RuO}_{2}$. 


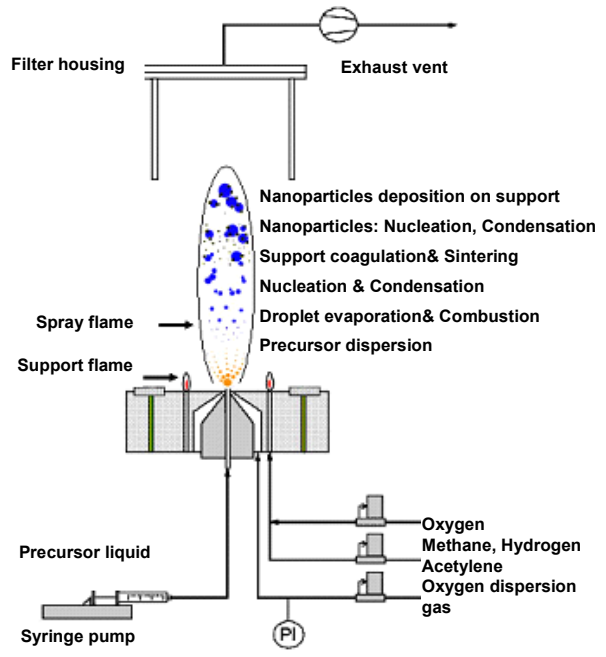

Figure 1: Schematic of the FSP experimental setup for the synthesis of nanoparticles [8].

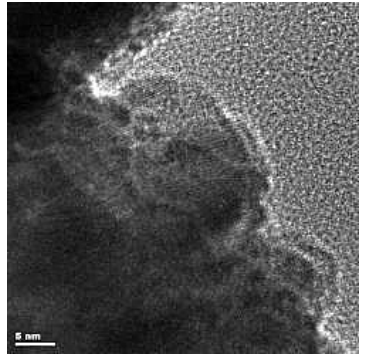

A)

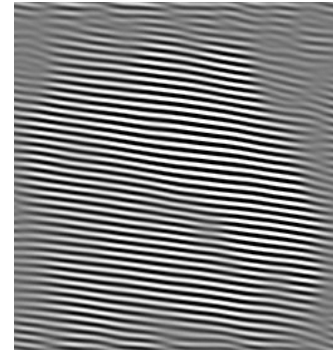

B)

Figure 2: A) HRTEM images of $\mathrm{TiO}_{2}-\mathrm{RuO}_{2}$; B) HRTEM images of $\mathrm{TiO}_{2}$ $\mathrm{RuO}_{2}$ samples.

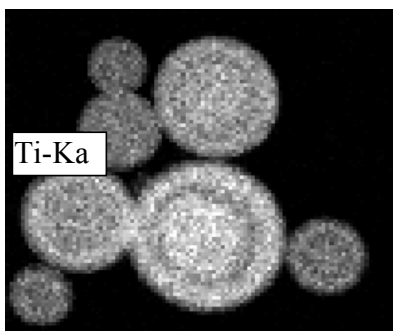

A)

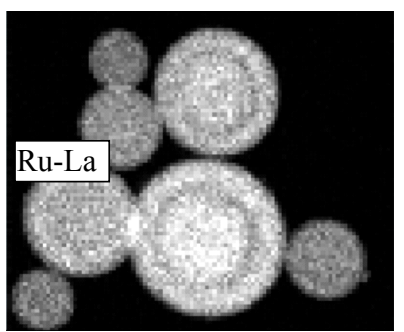

B)

Figure 3: HREM gives the EDS an elemental composition signal corresponding to: A) Ti; B) Ru. 


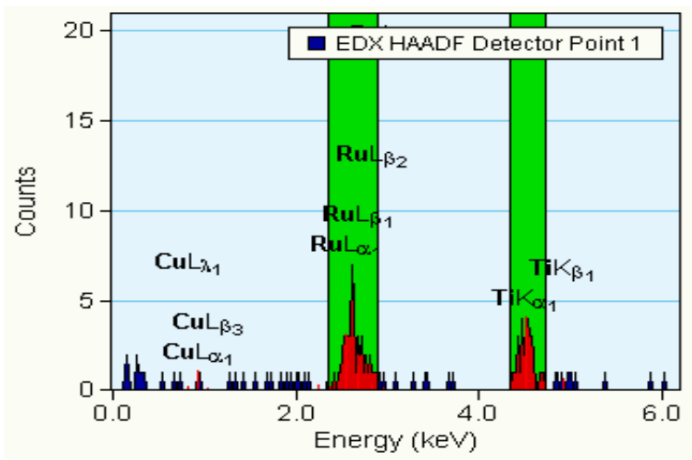

Figure 4: HREM gives the EDS an elemental composition signal corresponding to $\mathrm{Ti}$ and $\mathrm{Ru}$.

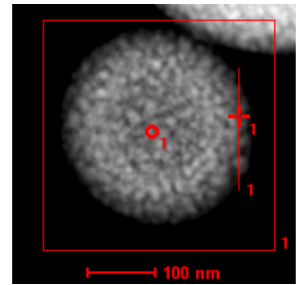

A)

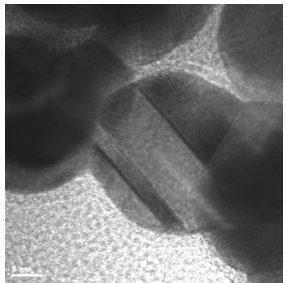

B)

Figure 5: A) Morphologies of the flame made sphere $\mathrm{TiO}_{2}-\mathrm{RuO}_{2}$; B) HREM crystal defects of the flame made sphere $\mathrm{TiO}_{2}-\mathrm{RuO}_{2}$.

\section{Preliminary engine test}

The DPF regeneration tests were conducted during 10 hours and performed by using a single cylinder engine AVL 5804. The test parameter is presented in Table 1. Test was performed for standard and optimized-experimental DPF. One of the filters studied was of the $\mathrm{SiC}-\mathrm{Ti}_{4} \mathrm{O}_{7}-\mathrm{TiO}_{2}-\mathrm{RuO}_{2}-\mathrm{DPF}$ system, called experimental DPF, while the other was of $\mathrm{SiC}$ composition-DPF standard.

Figures 6 and 7 illustrates temperature dependence of average concentration of particulate matter Figure 6 and average shoot burning rate Figure 7, obtained under different temperature conditions. Those data suggests that the process of burning soot on DPF was activated by non Pt-catalyst

Table 1: $\quad$ Test engine parameters.

\begin{tabular}{|l|l|}
\hline Engine type & $5804 ;$ 4-valve./cyl; DOHC \\
\hline Displacement & $0,51 \mathrm{dm} 3$ \\
\hline Torque & $\operatorname{max.} 55 \mathrm{Nm} / 2000 \mathrm{rpm}$ \\
\hline Power & $\max .16 \mathrm{~kW} / 3500 \mathrm{rpm}$ \\
\hline
\end{tabular}




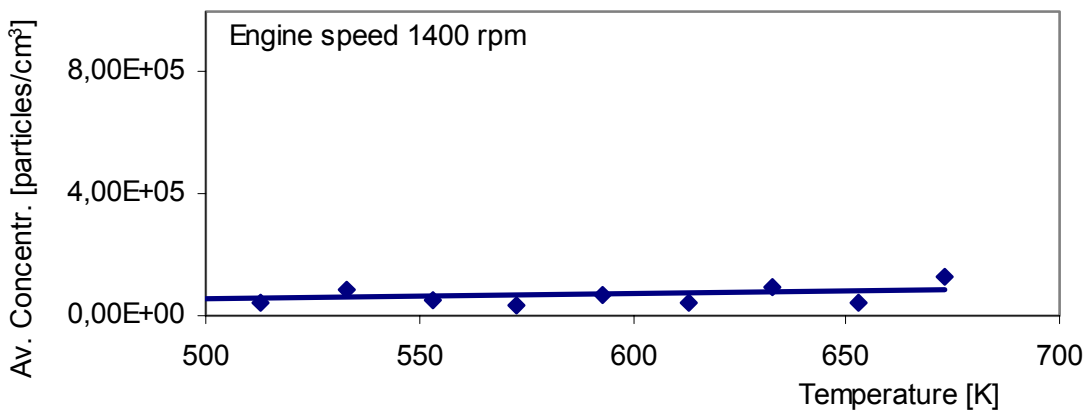

Figure 6: Average concentration of particulates from the test bed with the used test engine species.

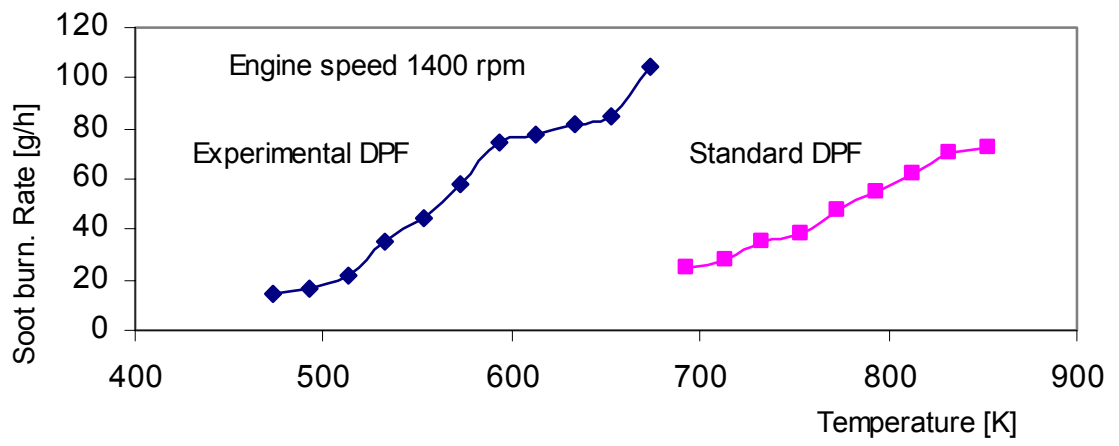

Figure 7: Average soot burning rate as a function of temperature and engine speed.

\section{Recovery of waste heat from the exhaust of automotive engines}

The second part of this work presents a design and performance measurements of a prototype thermoelectric generator mounted on self-ignition (Diesel) engine.

The heat exchanger delivers heat power received from the exhaust gases to the structure of TE modules. Due to the high speed of the exhaust gases, the heat exchange surface area in the heat exchanger should be increased by using the ribbing, grooving and protrusions which would introduce a turbulent flow allowing the increased flow of heat due to convection [1,2]. Heat absorption from gases should occur on a relatively short distance, due to the possibility of increasing the back pressure which would contribute to the changing operating conditions and limiting the engine power.

The paper [1] puts together the comparison of testing designs of thermoelectric generators and exchangers using the exhaust gas heat. On the basis of test results of the thermoelectric generators under research, the design issues can be divided into three groups: a) related to design of the heat exchanger 
allowing the absorption of the sufficient amount of heat energy from the gases, b) related to the selection of materials for the construction of the TE modules and their installation, c) related to the selection of the appropriate cooling system to ensure significant heat power exchange at low ambient temperature. The development of heat exchange systems could allow for the creation of generators of a relatively large capacity based on the already known thermoelectric materials.

The heat exchangers presented in the paper [1] were created in the direct contact with gases and TE modules. Such a solution requires more space, which limits their potential mounting location. The optimum conditions of TE module operation was ensured by using the ribbing of different surface areas depending on the exhaust gas temperature in the given spot within the exchanger. In this type of designs it is difficult to protect the TE modules from the effect of momentary overheating and to ensure the optimum operating conditions. This leads to the situations in which the modules based on materials not resistant to high temperature operate in lower than optimum temperatures at the same time being exposed to damage due to overheating. The transport of heat absorbed from the gases to the TE modules in the paper [5,6] was provided by the carrier medium which was the mixture of precious gases He and Xe. The flow control enabled the control of proper operating parameters of the generator. The location of the thermoelectric generator is an important factor, decisive of its operability. The TEG generator can be installed on the exhaust pipe [1] immediately behind the collector, between the collector and the catalytic converter or behind the catalytic converter. In the first location the exhaust gas temperature is the highest, allowing the high performance of the generators. The manufacturer's approach to the equipment located in front of the catalytic converter is however negative due to the impact it may have on the operation of the catalytic converter resulting from the decreased temperature of the gases in the outlet. The purpose of this paper was to design and test the model thermoelectric generator located behind the catalytic converter. The tests were aimed at determining the distribution of temperature inside the heat exchanger the engine power balance at different rpm and load conditions.

\section{Engine test}

The tests were performed using the self-ignition engine of $1.3 \mathrm{dm}^{3}$ displacement, with the direct common-rail injection and the Automex eddy-current brake dynamometer (Tab. 2). The engine was controlled by a modified electronic system. The preliminary measurements of the heat exchange mounted on the exhaust system of the engine were conducted on the engine test bed.

The tests were performed for the engine parameters including the operating range used in the real operation in road conditions. The authors selected the parameters based on their own experience. Full load characteristics of the engine were used for testing. To give the full picture of the operating conditions of the generator the measurements were taken in the load characteristics conditions at selected engine speeds, allowing the operation of the heat exchanger in the broad loading range (20-120 Nm) (Fig. 8,9). 
Table 2: $\quad$ Engine and brake specifications.

\begin{tabular}{|l|c|}
\hline \multicolumn{2}{|c|}{ Engine specification } \\
\hline Capacity & $1.3 \mathrm{dm}^{3}$ \\
\hline Engine power & $51 \mathrm{~kW} / 4000 \mathrm{rpm}$ \\
\hline Torque & $180 \mathrm{Nm} / 1750 \mathrm{rpm}$ \\
\hline Cylinders & 4 \\
\hline Valves & 16 \\
\hline Injection system & common rail \\
\hline \multicolumn{2}{|c|}{ Brake specification } \\
\hline Type & AMX $-210 / 100$ \\
\hline Maximum power & $100 \mathrm{~kW}$ \\
\hline Maximum torque & $240 \mathrm{Nm}$ \\
\hline Maximum rpm & $10000 \mathrm{rpm}$ \\
\hline
\end{tabular}

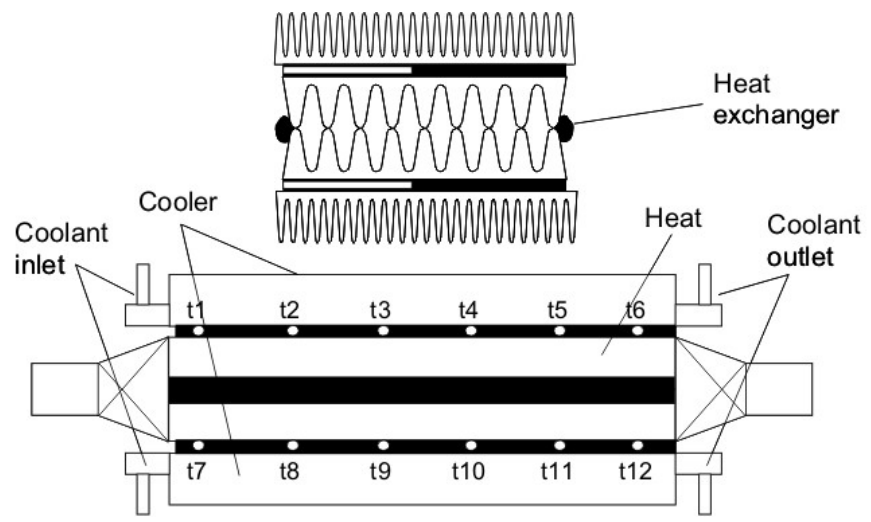

Figure 8: Cross-section of the thermoelectric generator.

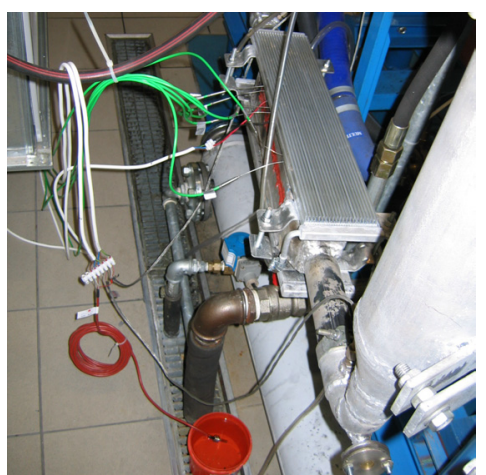

Figure 9: Picture of the thermoelectric generator mounted on the exhaust system of the self-ignition engine. 
Two variants of heat exchangers were tested. The difference between them was related to the modification of the inlet and outlet cone. The first variant caused the exhaust gases to cool down in the first stage of the flow through the recuperator, which resulted in lowering the temperature in the second part of the recuperator. The test results presented are for variant two with the improved exhaust gas flow conditions.

In order to compare the temperature distribution on the upper and lower cooler the temperatures were measured at $2300 \mathrm{rpm}$ and 20-120 Nm load. Also the temperature distribution on the lower cooler was presented at engine speeds of 1700 and $3300 \mathrm{rpm}$. Also the power received from the exhaust system was compared; the power received by the agent flowing through the cooler was calculated.

\section{Results}

The distribution of temperatures between the upper and lower cooler and the exchanger differs both in the temperature level and distribution in the particular measurement points (Fig. 10). The distribution of temperatures in the lower cooler is more uniform, which means the flow of exhaust gases, or rather the heat absorption by the lower part of the heat exchange is more efficient as compared to the upper part. It is most probably due to the less turbulent flow of the exhaust gases in the lower part of the exchanger.

The testing of the temperature distribution was performed at different engine speeds: $2300,3300 \mathrm{rpm}$. The temperatures received at lower engine speed are higher, even though the difference of temperature of the exhaust gases measured for the both engine speeds in front of and behind the recuperator is at every engine load point higher for the $3300 \mathrm{rpm}$ by $50^{\circ} \mathrm{C}$ on average. However, in the first case the coolant flow of $21 \mathrm{l} / \mathrm{h}$ was used.

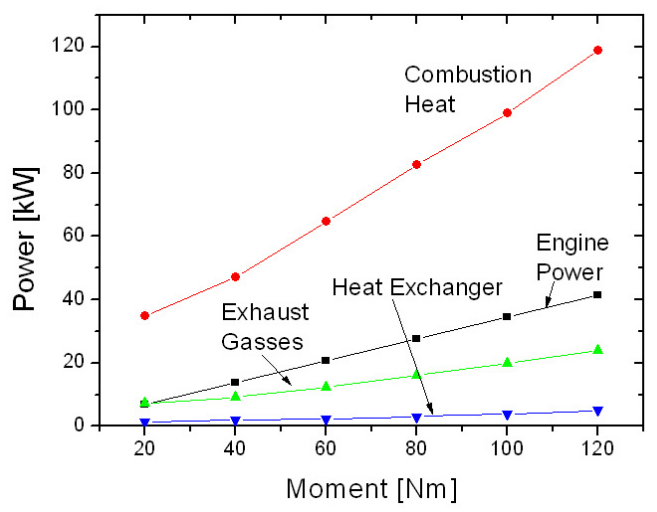

Figure 10: Generated and recuperated heat comparison at engine speed 3300 rpm and different loads. 
At $3300 \mathrm{rpm}$ the flow was 10 times higher, which lead to smaller differences in coolant temperature in front of and behind the coolers, and at the same time to the greater efficiency of heat absorption from exhaust gases. This situation is illustrated by Figure 11, which shows that the most efficient operation of the system was at $3300 \mathrm{rpm}$. The recuperator built enabled the maximum recuperation of $5.2 \mathrm{~kW}$ at fuel consumption of $4.6 \mathrm{~kg}$, air consumption of 87 $\mathrm{kg} / \mathrm{h}$ and the resulting combustion heat of $118 \mathrm{~kW}$ at engine power of $42 \mathrm{~kW}$ (engine speed of $3300 \mathrm{rpm}$ and $120 \mathrm{Nm}$ load). The power values obtained at 1700 and $2300 \mathrm{rpm}$ speeds are at the similar level.

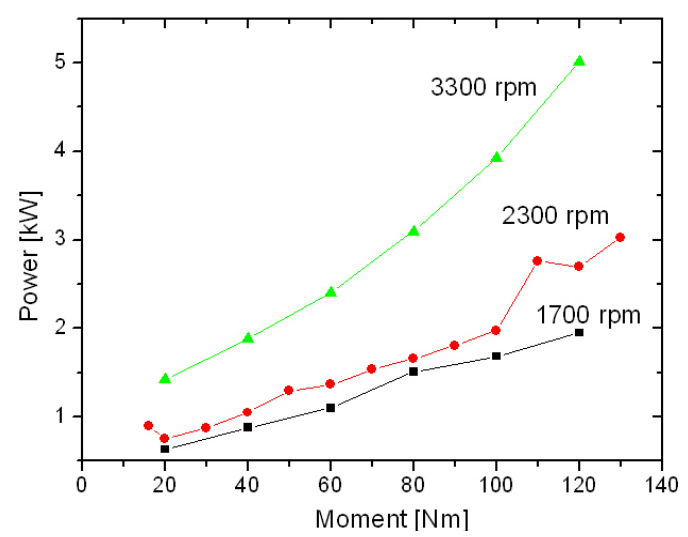

Figure 11: Recuperated power with different engine speeds and loads.

\section{Conclusion}

First part: Phenomenon of hollow part $\mathrm{TiO}_{2}-\mathrm{RuO}_{2}$ gives possibilities to reduce quantity of $\mathrm{Ru}$ and other precious metal catalyst in the DPF. Dynamically process of regeneration was started at $650 \mathrm{~K}$ for experimental DPF. Normally this process without catalyst was started in the range of temperature between $750-800 \mathrm{~K}$.

The composite of $\mathrm{SiC}^{-} \mathrm{Ti}_{4} \mathrm{O}_{7}$ is used as the thermal barrier for increasing thermal shock resistance of the DPF. The nanoparticles sphere of $\mathrm{Ti}_{4} \mathrm{O}_{7}$ has the smallest surfaces area and this shape restrained the crack propagation of DPF material. Technique used in this experiment indicating of the low cost of DPF fabrication.

The experiment aims further to study the high heat of oxidation reaction of hydrocarbon and carbon oxide to dioxides.

Second part: The performance of the heat exchanger system built forms the basis for continuing the process of design optimization. The designed model heat exchanger allowed the recuperation of 0.4 to $5.2 \mathrm{~kW}$ of power at the engine operation parameters used, which assuming the $5 \%$ operability of the thermoelectric modules could allow the generation of 20 to app. $200 \mathrm{~W}$ of power. The coolant temperature on inlet was $17-20^{\circ} \mathrm{C}$. If the coolant from the 
engine cooling system was used on the cooler inlets, the difference in inlet and exhaust coolant temperature would be much smaller. In this case the possibility of continuous flow adjustment depending on the momentary engine operating parameters will play a significant role as well as the high efficiency of the thermoelectric materials.

The obtained level of temperatures of the exhaust gases in the modern selfignition engines opens the prospects for power recuperation at a satisfactory level provided that cheap thermoelectric materials of sufficient durability and efficiency will be used. The research conducted indicates that the recuperator built can obtain a higher performance when embedded in the spark-ignition engine exhaust system. This research will be continued.

\section{References}

[1] Bell, L. E.: High efficiency thermoelectric waste energy recovery system for passenger vehicle applications. Advanced Combustion Engine $R \& D$. Progress Report pp 287-290, 2005.

[2] Birkholz, U.: Conversion of waste exhaust heat in automobile using fesi ${ }_{2}$ thermoelements. Proc. $7^{\text {th }}$ International Conference on Thermoelectric Energy Conversion, Arlington - USA, pp. 124-128, 1988.

[3] Diesel Particulate Filter technology Ed.T.V. Johnson, 2007.

[4] Discussion meeting on catalysis from first principles Lyon, France, July 5 8,2000 .

[5] Ikoma, K.: Thermoelectric module and generator for gasoline engine vehicle. Proc. 17th International Conference on Thermoelectrics. Nagoya, Japan, pp. 464-467, 1998.

[6] Serksnis, A.W.: Thermoelectric generator for automotive charging system. Proc. 11th Intersociety Conversion Engineering Conference. New York, USA, pp. 1614-1618, 1976.

[7] Stafford, N.: Catalytic converters go nano. Advances the Chemical Sciences. Chemistry World, 10 October 2007.

[8] Tani T., Mädler L., Pratsinis S.E.: Homogeneous ZnO nano. J. Nanopart 4, 337-343, Res. 2002. 